\title{
THE GROWTH AND ABSORPTION OF NUTRIENTS BY FERTILIZED AND UNFERTILIZED WHITE SPRUCE SEEDLINGS
}

\author{
By K. A. ARMSON ${ }^{1}$
}

\begin{abstract}
A study was made of the effects of fertilizer additions on the growth and development of white spruce seedlings during their second growing season. In terms of dry weight increment, unfertilized trees grew for only two-thirds of the total growing season available as compared with fertilized trees. The relative growth rate curve for the fertilized trees was smooth with none of the abrupt changes which marked the curve for the unfertilized trees. The pattern of height growth was changed for seedlings which were fertilized. Nutrient uptake rates particularly for phosphorus were different under the two treatments and it is suggested that these differences were related to different patterns of height growth development and root extension.
\end{abstract}

\section{INTRODUCTION}

The increasing use of fertilizers, particularly in forest tree nurseries, during the past few years has stimulated a renewal of interest in the movement of nutrient elements, their losses by leaching in soils and also the absorption of elements by seedling roots. Most of the early work on nutrient absorption in trees was done by German investigators early in the twentieth century (Bauer, 1910; Ramann and Bauer, 1912). A recent paper (Armson, 1965) briefly reviewed this work and also some of the more recent studies dealing with seasonal absorption by tree seedlings.

The majority of previous studies have been concerned with patterns of absorption during one or more growing seasons for seedlings growing under similar environmental conditions. A few studies have, however, compared the growth and absorption for seedlings which have been differentially fertilized (Tsuda, 1959). In studies on forest tree species little attempt has been made to establish if relationships exist between nutrient absorption and specific developmental stages of the tree. Dry weight has, for obvious reasons, been used almost exclusively as the measurement of growth.

\footnotetext{
${ }^{1}$ The author is Associate Professor of Forestry, Faculty of Forestry, University of Toronto, Canada. Financial support for this study was provided by the Timber Branch, Ontario Department of Lands and Forests, and the Ontario Research Foundation.
} 
Previous studies of the growth of white spruce (Picea glauca (Moench) Voss) seedlings and their patterns of nitrogen, phosphorus and potassium absorption (Armson, 1960, 1965) dealt only with populatiuns growing under similar environmental conditions. Results of these studies demonstrated that in absolute terms, the larger a seedling becomes the greater the amount of nutrient absorbed, as might be expected. However, if the rate of nutrient absorption is related to the relative growth rate then it is clear that the rate of absorption for an element such as nitrogen is greater for a small seedling-following germination-than it is for a larger seedling toward the end of the growing season. In any discussion of nutrient absorption it is, therefore, important to distinguish between the amount absorbed in absolute terms, and the rate of absorption expressed as a function of the relative growth rate of the seedling.

The present study was made with white spruce seedlings during their second growing season. One half of the seedlings received additional nitrogen and phosphorus fertilizers during this period, the remainder received none. The growth and patterns of nutrient absorption for these seedlings during the previous year (first growing season) has already been reported (Armson, 1965). During this first year all seedlings received the same fertilizer treatments. The purpose of the present investigation was to determine to what degree differential fertilization would affect the absorption patterns for three elementsnitrogen, phosphorus and potassium.

\section{Experimental Methods and Materials}

White spruce seed, Seed Zone 5, Ontario Department of Lands and Forests, was sown at Swastika Nursery (Lat. $48^{\circ} \mathrm{N}$, Long. $80^{\circ} 27^{\prime} \mathrm{W}$ ) in October, 1959. Prior to sowing, the seedbed soil was treated with the following fertilizers- 300 pounds per acre of $0-30-10 ; 200$ pounds per acre of urea formaldehyde and 350 pounds per acre of triple superphosphate. The major nutrients contained in these fertilizers were: nitrogen 78 pounds per acre, phosphorus 110 pounds per acre and potassium 25 pounds per acre. During the first (1960) growing season, nitrogen as ammonium sulphate was applied twice as a top dressing at the rate of 16 pounds of nitrogen per acre. During the second growing season (1961), one set of seedlings, the fertilized trees, received nitrogen as ammonium nitrate at the rate of 20 pounds per acre applied five times during the growing season between May 25th and September 7th. Thus a total of 100 pounds nitrogen per acre was applied. Phosphorus as a triple superphosphate was applied four times during the season at the rate of 50 pounds of phosphorus per acre, for a total of 200 pounds during the growing season.

Sampling procedures were similar to those used in previous studies. Four sampling blocks were laid out in the seedbeds; the width of the block corresponded to seedbed width and the length was 30 feet. Fifteen sampling strips each two feet wide were marked by numbered stakes and randomly located within each block. Fifty seedlings were selected at random from a sampling strip in each of the four blocks in the fertilized beds and four samples from the four blocks in the unfertilized, thus the total number of seedlings sampled each time was 400. Fourteen samplings were made beginning on May 12, 1961, 
and ending on November 4, 1961. The interval between samplings was approximately two weeks.

Seedlings were shipped by express to the laboratory where the root systems were carefully washed free of soil. Total height of each seedling was measured and the seedlings were separated into their component organs-secondary needles, stem, primary needles and roots. Seedlings were dried at $80^{\circ} \mathrm{C}$ in a forced draft oven; after drying, all organs were weighed. Samples of each organ were taken for nitrogen, phosphorus and potassium analyses by conventional analytical methods. Thus four separate determinations for each element were made on organs from fertilized trees and four on organs from unfertilized trees. Total nutrient contents per seedling were calculated from these data. In this paper the means of each set of four values are used unless otherwise stated.

During 1963, height measurements were made on 60 white spruce selected at random in production seedbeds at Orono Nursery (Lat. $43^{\circ} 59^{\prime} \mathrm{N}$ Long. $78^{\circ} 36^{\prime} \mathrm{W}$ ) during their second growing season. Measurements were made at two weekly intervals from June until early September. No nutritional studies were made of these trees.

\section{RESULTS}

Figure 1 shows the cumulative dry weight curves for the fertilized and unfertilized trees. The unfertilized trees show a sigmoidal curve with no dry weight increase after late August, whereas the fertilized trees show essentially a linear increase from mid-June to early November when the last samples were taken. Further sampling was not possible because the ground was frozen. The relative growth rate percent was calculated for each set of seedlings, based on fitting a freehand curve to each set of data and then reading from the curve dry weights at 10-day intervals. The relative growth rate percent was then calculated using the formula:

$$
\text { R.G.R. } \%=\frac{W_{2}-W_{1}}{W_{1}} \times \frac{1}{T_{2}-T_{1}} \times 100
$$

where $W_{1}$ and $W_{2}$ are the dry weights at times $T_{1}$ and $T_{2} ; T_{2}-T_{1}=10$ days. The use of the linear formula used above is subject to certain criticisms; the major one being that an exponential expression-

$$
\log _{\mathrm{e}} \mathrm{W}_{2}-\log _{\mathrm{e}} \mathrm{W}_{1} \times \frac{1}{\mathrm{~T}_{2}-\mathrm{T}_{1}}
$$

is more appropriate. However, if the interval $T_{2}-T_{1}$ is short, the values calculated using the linear formula are very similar to those calculated on an exponential basis (Armson, 1960). In the present study, values were determined by both methods but those derived using the linear formula only are presented for simplicity and because their use does not invalidate the results or the conclusions drawn from them.

The relative growth rates are shown in Figure 2. The fertilized trees attain a higher growth rate early in the season and the rate falls off smoothly, and is still high at the end of the season. The relative growth 


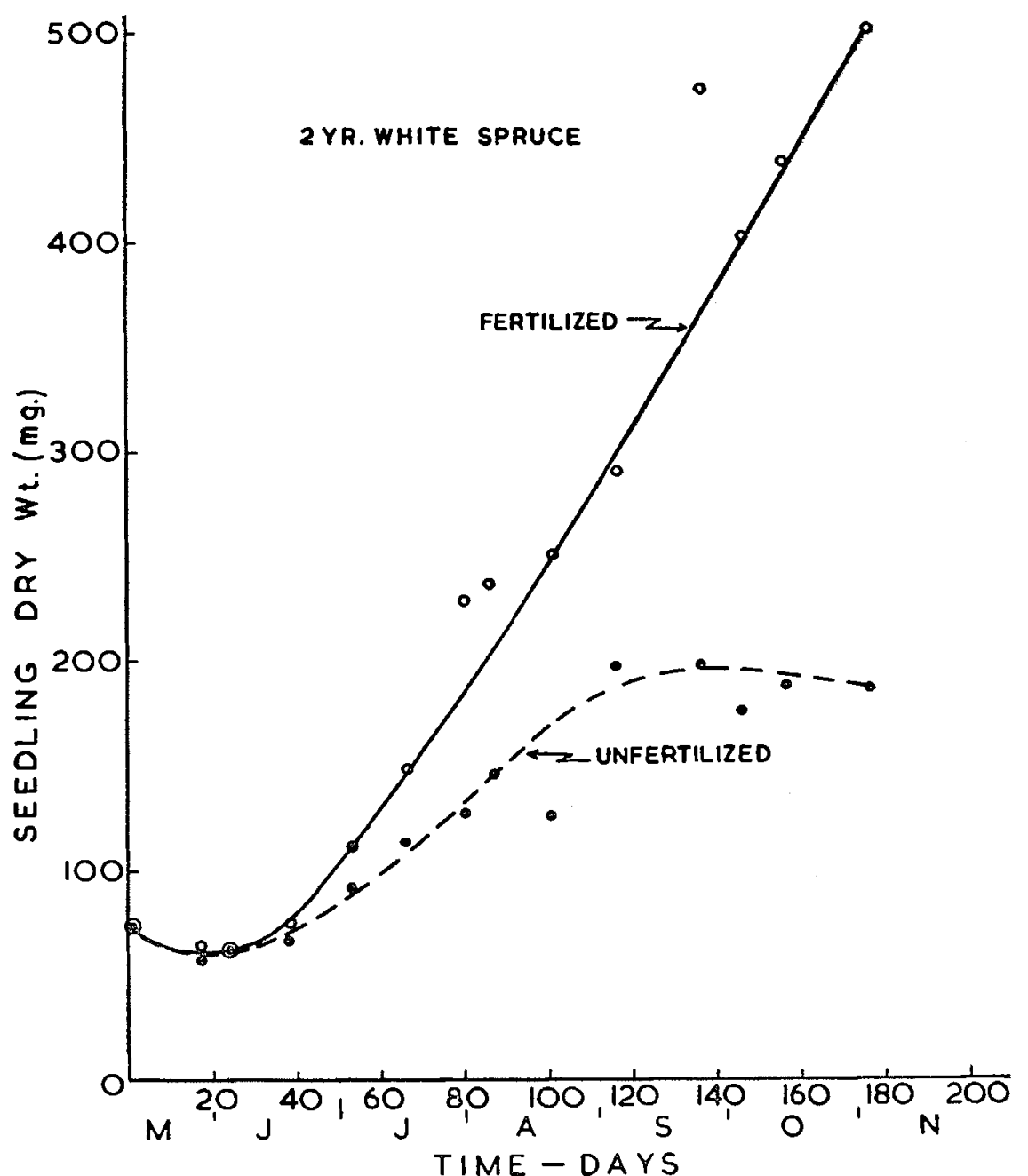

FIGURE 1. Seedlings' mean total dry weights plotted against time. Lines drawn freehand.

rate for the unfertilized trees decreased somewhat irregularly at first and then falls to zero in late September.

Mean seedling heights are plotted in Figure 3. Until mid-June the rate of height growth is similar for both fertilized and unfertilized trees. However, height growth for the unfertilized is over by early July, but growth continues until mid-July for the fertilized. Further, for the fertilized trees during the period from late August until late September, there is a second period of height growth. This second period of growth did not represent the flushing of buds which had already set, but rather the extension of shoots in which no true 
JUNE, 1966

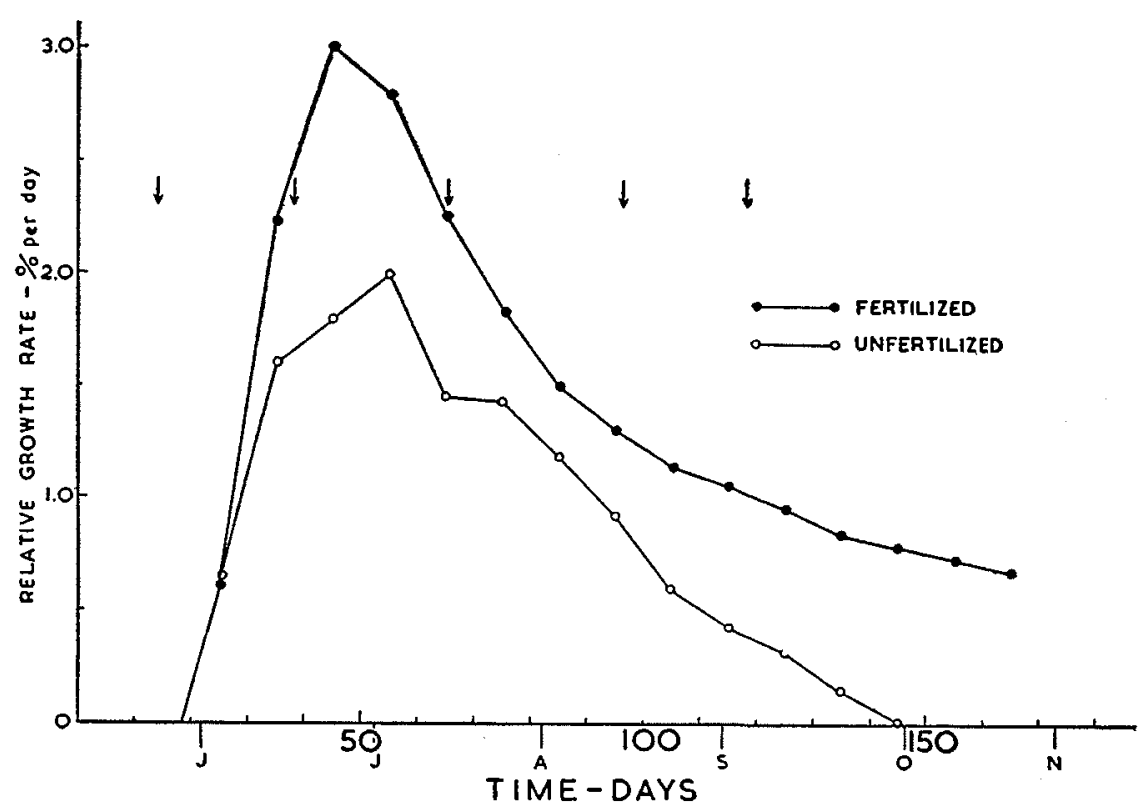

FIGURE 2. Relative growth rates plotted against time.

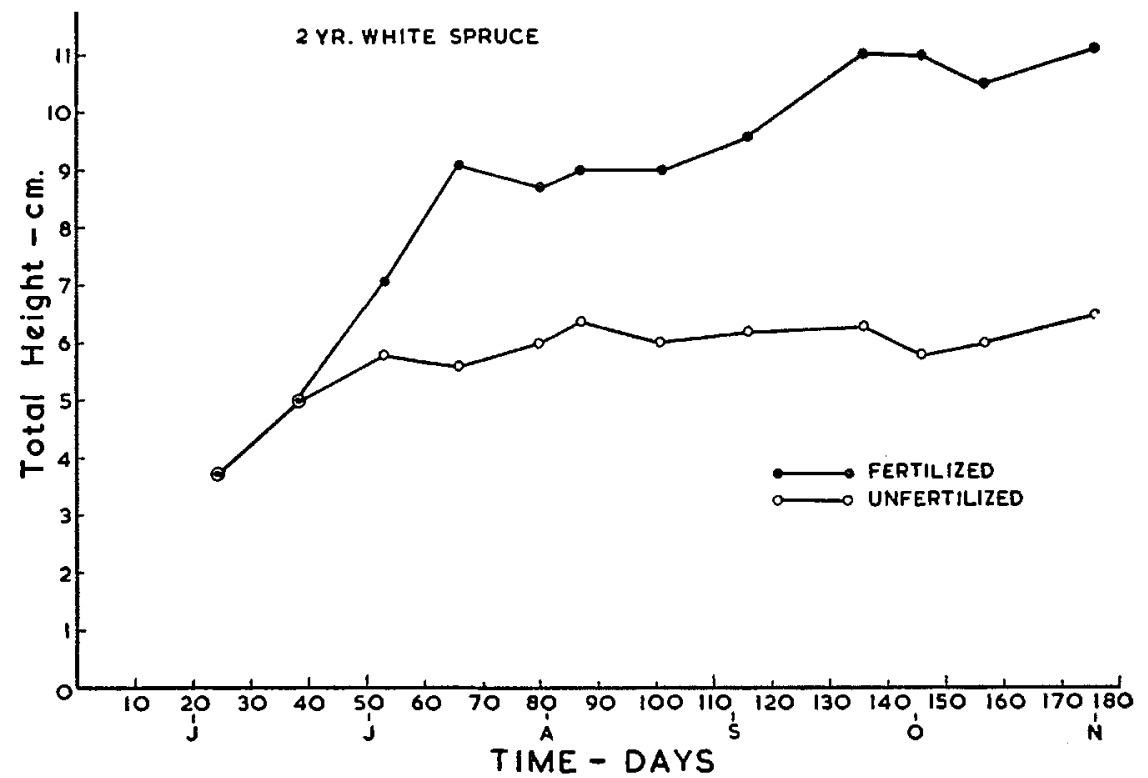

FIGURE 3. Mean heights of seedlings plotted against time. 


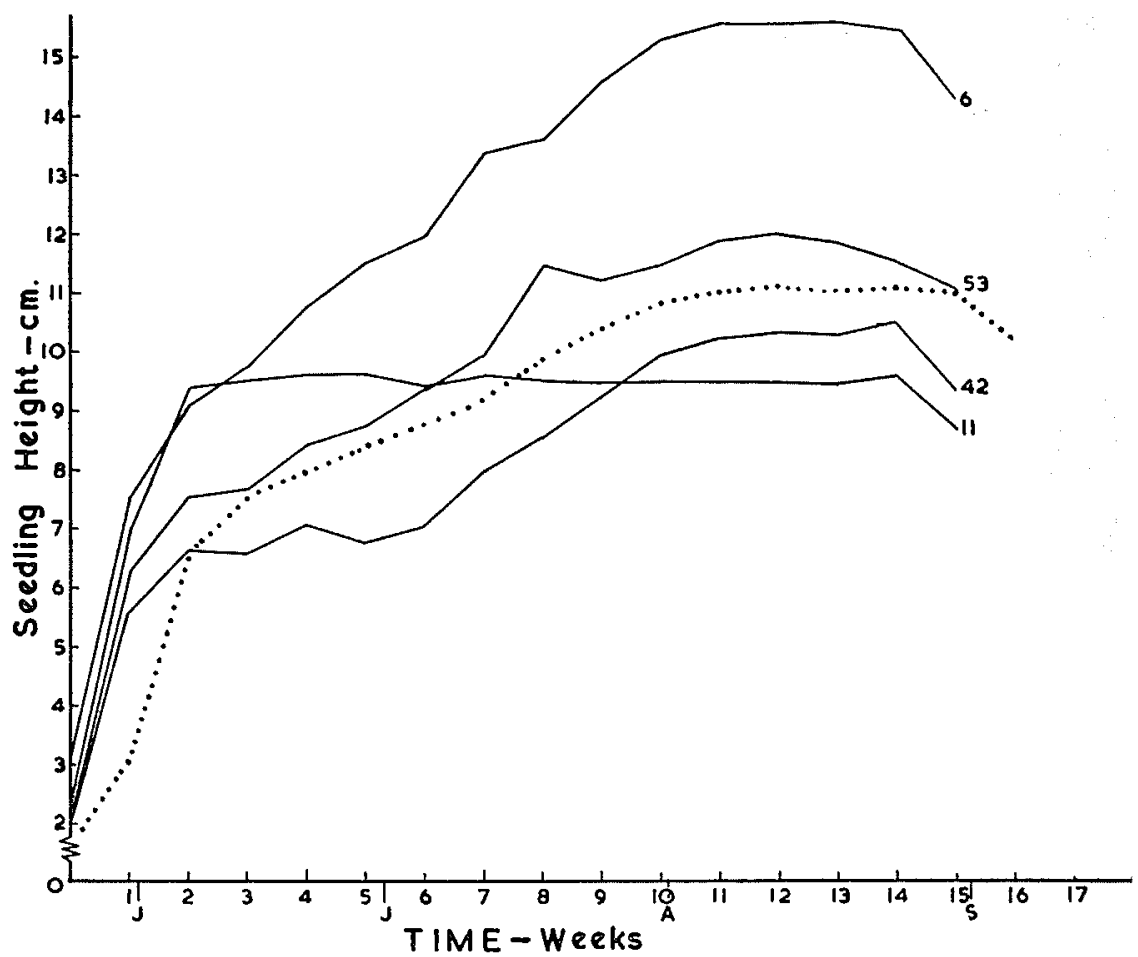

FIGURE 4. Height growth measurements for Orono white spruce during second growing season. Data for seedlings No. 6, 11, 42 and 53. Mean of 60 seedlings . . .

terminal bud had yet formed. The data are mean values and, because of this and the fact that the sampling was destructive, it was not possible to determine the nature of height growth patterns for individual trees; although it appeared that while virtually all of the unfertilized trees had set buds by mid-July, this was only true for a small proportion of the fertilized trees.

To determine whether varying individual patterns existed, the height patterns of white spruce trees in their second growing season were measured at Orono nursery. These trees were well-fertilized and irrigated. A selected series of these patterns is shown in Figure 4. It will be seen that tree No, 11 shows a pattern characteristic of the unfertilized and that tree No. 6 shows height growth continuously from late May until early August. Trees 53 and 42 show a decline in growth in June but this is followed by increased growth in July. The average height growth pattern for the 60 measured trees is indicated in Figure 4 and it is apparent that it is of the same form as that in Figure 3. It may be deduced, therefore, that the mean height growth of fertilized seedlings as shown in Figure 3 is a result of varying patterns of height growth by individual seedlings as indicated in Figure 4. 


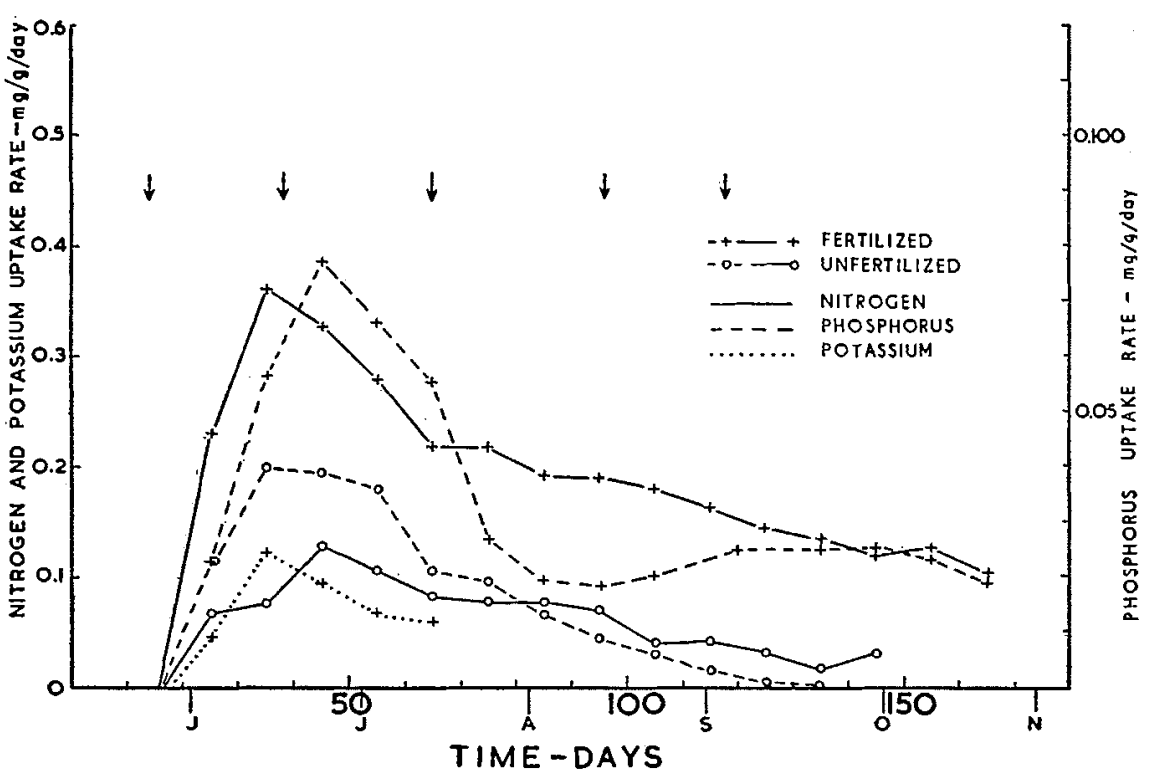

FIGURE 5. Nutrient uptake rates for fertilized and unfertilized trees. Arrows $\downarrow$ indicate times of fertilizer addition to fertilized trees.

Associated with the increase in height of the fertilized trees (Figure 3) there was an increase in number of secondary needles; thus at the end of the season the unfertilized trees had a mean of 94 needles, whereas the fertilized trees had 180 needles. The increase in numbers of needles was associated with the increased shoot extension.

Nutrient uptake rates were calculated using a technique described previously (Armson, 1960, 1965). These rates are illustrated in Figure 5. For nitrogen, although the patterns are similar, it will be noted that the uptake rate for the fertilized trees is at all times much higher than for the unfertilized trees. The phosphorus uptake for the fertilized trees rises to a maximum in 1ate June, falls off to a minimum in early August, and rises to a higher level in September. In the unfertilized trees the maximum rate of phosphorus uptake is in midJune and it becomes progressively less during the remainder of the season.

Potassium uptake rates were not determined for the unfertilized trees because of the lack of any well-defined relationship between potassium content and seedling size. For the fertilized trees the potassium uptake initially parallels the relative growth rate until mid-July, after which time there was no welldefined relationship between potassium content and seedling size.

\section{Discussion}

If dry matter increase is used as the criterion of growth, it will be seen that the unfertilized trees are growing for only two-thirds of the period available 
and achieving a final size of less than half that of the fertilized trees. Thus in a given location, improper soil management as illustrated here by inadequate fertility may prevent utilization of the climatologically determined growing season. Figure 1 shows similar curves to those obtained by Tsuda (1959) for fertilized and unfertilized Japanese larch.

One of the effects of adding fertilizer at periodic intervals during the growing season has been that the relative growth rate curve is smooth with no abrupt changes of the type which occur in the unfertilized trees. It might be inferred that a smooth growth curve represents a more satisfactory physiological state than one in which there are sharp changes. No evidence, however, other than size is presented to suggest that the fertilized trees are in fact more desirable for use.

Fertilization has resulted in twice as many secondary needles, compared with the unfertilized trees. This large increase in photosynthesizing organs would no doubt be of significance in terms of outplanting, other factors being similar.

The effect of fertility on height growth is interesting. It indicates that for seedling white spruce, height growth is subject to considerable control by means of manipulation of soil fertility. The pattern of growth indicated in Figure 3 has also been noted by Kozlowski and Ward (1957) for white spruce seedlings in their third growing season in a nursery. They also noted that the seedlings were grown in a soil of high fertility. Farrar (1961) working with Norway spruce (Picea abies (L) Karst.) found three patterns of shoot growth similar to those in Figure 4 occurring in seedlings of five provenances subjected to varying photoperiods. He found no consistency in pattern for individual seedlings when treatments were repeated and suggested that the control was internal and non-genetic. Lanner (1963), however, found for knobcone pine (Pinus attenuata Lemm.) that one provenance showed a bimodal pattern of height growth whereas the remaining provenances showed a sigmoidal curve. This pattern was repeated in a second growing season and he suggested that it was a genetic trait. He also noted that where the bimodal pattern prevailed a bud was formed in June and the second flush was due to shoot extension at the base of the bud. For white spruce, in the present study, height growth after the initial flush was not a result of shoot extension at the base of a terminal bud.

It is apparent that the height growth pattern is subject to environmental control, but the possibility also remains that there may be a genetic control involved since some seedlings do not respond in the same way as others under similar conditions. It will be noted that the seed used in the present study was mixed and identifiable only as originating from Zone 5-a large geographic area in northern Ontario - thus the probability of wide genetic variation would be large.

If the nutrient uptake rates are considered (figure 5), it will be noted that the major differences between those for the fertilized and unfertilized trees are first, that the order of magnitude is greater for the fertilized trees-as might be expected. Second, that the fertilized trees show a second period of increase in phosphorus uptake rate in late August, whereas the unfertilized do not. 
The pattern for the fertilized trees is similar to that which has been previously noted for white spruce in both its first and second growing seasons (Armson 1960, 1965). In both these previous studies the trees were grown in soils of high fertility.

From the results of the present study, it would appear reasonable to deduce that the pattern of phosphorus uptake which hitherto has been associated with white spruce seedlings is in fact related to both the fertility of the soil and also the ontogeny of the plant itself. The periods of increasing phosphorus uptake are coincident with periods during which the spruce seedling is growing in height. Height growth is related to increased soil fertility, which in turn is associated with increased absorption of nutrients. The consistent difference between nitrogen uptake patterns, which in all instances are similar to those of relative growth rates, and phosphorus uptake would suggest that these differences may likely be related to differences in absorption, and/or function of phosphorus compared with nitrogen.

Phosphorus is a constituent of the cell and is essential for the development of meristematic tissues. Studies in many other plants have indicated relatively high levels of phosphorus in the apical and root meristems. The writer has demonstrated this occurrence for white spruce seedlings using ${ }^{32} \mathrm{P}$. Nitrogen occurs as a major component of protein and exists in highest concentrations in foliage tissues. Phosphorus in the most available form taken up by roots $-\mathrm{H}_{2} \mathrm{PO}_{4}^{-}(\mathrm{Black}, 1958)$-is relatively immobile in the soil and hence continued or increased absorption is largely dependent on extension of roots in the soil, whereas nitrogen particularly in the nitrate form is freely moveable.

Richardson (1957) among others has demonstrated a link between the production of hormone by active apical meristems and the stimulation of root growth. It is, therefore, possible to postulate a mechanism to explain the differences in height growth in relation to increase in phosphorus supply. During the period of initial height growth for both unfertilized and fertilized trees, hormone production is high and in a suitable soil environment root growth is extensive with a concomitant increase in the rate of phosphorus absorption-as well as other elements. At the end of the first period of height growth (early July) the rate of root growth decreases in relation to hormone supply and/or a less favourable root environment. If an optimal level of phosphorus exists in the soil, i.e., as a result of fertilizer phosphorus addition, then the rate of phosphorus absorption will not decrease to as low a level as that when the level of soil phosphorus is below optimum, i.e., in the unfertilized soil. Consequently, those seedlings which are capable of further apical meristem activity will have a supply of phosphorus available for such growth from the soil with higher phosphorus supplying capacity. Further or continuing meristematic activity will result in further hormone production which may in turn stimulate root extension resulting in increased phosphorus absorption.

The results of the present study would support, indirectly, this hypothesis. Its actual validity, however, is dependent on further experimental studies. 


\section{Literature Cited}

ARMSON, K. A. 1960. White spruce seedlings. The growth and seasonal absorption of nitrogen, phosphorus and potassium. For. Bull. No. 6. University of Toronto. pp. 37.

1965. Seasonal patterns of nutrient absorption by forest trees in Forest-Soil Relationships in North America. Oregon State University Press. pp. 532.

BAUER, H. 1910. Stoffbildung and Stoffaufnahme in jungen Nadelhölzesn. Natuw. Zeitsch. Forst. Lanv, 8, 457-498.

BLACK, C.A. 1958. Soil-plant relationships. John Wiley, New York. vi +332 pp.

FARRAR, J. L. 1961. Induced variation in the pattern of shoot extension in five seed sources of Picea abies (L.) Karst. Proc. 8th NE. Forest Tree Improvements Conf. pp. 14-20.

KOZLOWSKI, T. T. and R. C. WARD. 1957. Seasonal height growth in conifers. For Sci. $3: 61-66$.

LANNER, R. M. 1963. Growth and cone production in knobcone pine under interrupted nights. Res. Note No. 38, Pacific Southwest For. \& Range Expt. Station.

RAMANN, E. and H. BAUER. 1912. Trockensubstanz, Stickstoff und Mineralstoffe von Baumarten während eiser Vegetationsperiode. Jahrbuck J. wiss Bot. 50-67.

RICHARDSON, S.D. 1957. Studies of roor growth in Acer saccharinum. VI. Further effects of the shoot system on root growth. Proc. ned. Atad. Wet. 60c(5).

TSUDA, K. 1959. Manure examination for Larix. XI. Studies on the seasonal changes of the absorbed nutrients. Ann. Report Hokkaido For. Expt. Sta. (1958) 67-73. 